\title{
Measuring Scientific Input and Output: Proposing Designs
}

Mohammad Hassanzadeh

Associate Prof, Head, Knowledge and Information Science Dept

Faculty of Management and Economics

Tarbiat, Modares University, Tehran- Iran

hasanzadeh@modares.ac.ir

Tahereh Bozorg Bigdeli

Senior Researcher, Ayandeh Aoozane Ata

Modares S\&T Park

Tehran- Iran

bbigdelit@gmail.com

ABSTRACT: Investment in $R \& D$ leads to the growth of nations. Countries which spends considerable amount of money for $R \& D$ are likely to get both direct and indirect benefits. Thus investments in Science is seen as the indication of knowledge production and growth of a country. Measuring the money invested in science and output is not always easy. The main issue is that, finding the output in research and development is a complex process. In industries it is an easy task to measure the input and correlate with the output. Science is not equivalent to industry in measuring the input and output. In science measurement systems, the document output is used as a yardstick. Since financial inputs play crucial role in progress of $R \& D$ systems, taking them in account when calculating the efficacy of this system will provide us with clearer image of $R \& D$ performance. The current paper intends to address the monetary issues in the research and development process to provide an optimum financial model. To achieve the objective, we try to find the cost, expenses and output and correlate with suitable products. We produce data on papers, citations and other impact and selected a particicular institution which has a good number of students and faculty. The selected instituion has a network of universities in Iran.

Keywords: Scientific Input, Input and Output Analysis, Return of Investment, Science model, Scientometrics

Received: 12 May 2018, Revised 20 June 2018, Accepted 4 July 2018

DOI: $10.6025 / \mathrm{jism} / 2018 / 8 / 4 / 115-122$

(C) 2018 DLINE. All Rights Reserved 


\section{Introduction}

Most of scientometrics studies focuses on the determined document based outputs of the R\&D systems. Since financial inputs play crucial role in progress of $R \& D$ systems, taking them in account when calculating the efficacy of this system will provide us with clearer image of R\&D performance. This research aimed to focus more on financial aspects of R\&D performance in universities forward utilizing some sort of knowledge economy framework (Hassanzadeh, Akhgar and Navidi, 2014). For that, we strive to formulate the expenditure has been carried out in various levels of a university which results in a unit of scientific paper, highly cited paper, fruitful actors, and etc.

Return on Investment (ROI) is defined as the ratio of gains from investment and is used normally as an index to measure the performance and evaluate the efficiency of an investment on some project or initiative or compare the efficiency of a number of different investments. ROI was formulated to measure the amount of return on a particular investment, against the investment's cost. Return on investment is divided by the investment costs. The result is expressed as a percentage or ratio. The classic formula is as following:

$$
\text { ROI }=\frac{(\text { Gain from Investment }- \text { Cost of Investment })}{\text { Cost of Investment }} \times 100
$$

In the formula, "Gain from Investment" refers to the proceeds obtained from the sale of the investment of interest. Because ROI is measured as a percentage, it can be easily compared with returns from other investments, allowing one to measure a variety of types of investments against one another (Investopedia: ROI, 2018).

ROI can be used in conjunction with Rate of Return, which takes in account a project's time frame. One may also use Net Present Value (NPV), which accounts for differences in the value of money over time, due to inflation. The application of NPV when calculating rate of return is often called the Real Rate of Return.

\section{Social Return on Investment}

Traditional ROI formula was criticized because of its deficient in calculating the real return and benefits of the investments. Some investors and businesses have taken an interest in the development of a new form of the ROI metric, called "Social Return on Investment," or SROI which intended to cover social and environmental metrics that currently do not reflected in conventional financial accounts. It was initially developed in the early 2000s and takes into account broader impacts of projects using extrafinancial value. Social return normally generalizes the return measures to social context and helps understand the value proposition of certain ESG (Environmental Social \& Governance) criteria used in socially responsible investing (SRI) practices. Undertakings for sustainability in terms of expenditures on infrastructures to reduce energy consumptions and other types of investments which may not be returned completely but have an immediate cost which may negatively impact traditional ROI - however, the net benefit to society and the environment could lead to a positive SROI. (Investopedia: ROI, 2018).

Social media has imposed a big change to social relationships and social network as an emerging concept deals with centrality and betweenness of actors in a network. In a social network people interact with each other by seeing and liking or mentioning posts and updates. These are new flavors of ROI that have been developed for particular purposes but are not accounted in terms of traditional formula. Similarly, marketing statistics ROI tries to identify the return attributable to advertising or marketing campaigns. So-called learning ROI relates to amount of information learned and retained as return on education or skills training. As the world progresses and the economy changes, several other niche forms of ROI are sure to be developed in the future (Investopedia: ROI, 2018). We can add other ROI indexes such as gained expertise, best practices, shared knowledge and savings because of repeated experiences.

Social return on investment (SROI) is a collection of techniques for measuring values that are not traditionally reflected in financial statements. These values may include social and environmental factors. They have been set to determine how effectively an enterprise leverage its capital and other resources to create value for the community beyond the organizational borders. While a traditional cost-benefit analysis is used to compare different investments or projects, SROI is used more to evaluate the general progress of certain developments, showing both the financial and social impact the corporation can have (Investopedia: SROI, 2018).

\begin{tabular}{lllllll}
\hline 116 & Journal of Information \& Systems Management & Volume & 8 & Number & 4 & December \\
\hline
\end{tabular}


SROI is useful to corporations because it can improve program management through better planning and evaluation. It can also increase the corporation's understanding of its effect on the community and allow better communication regarding the value of the corporation's work (both internally and to external stakeholders). Philanthropists, venture capitalists, foundations and other non-profits may use SROI to monetize their social impact, in financial terms.

A general formula used to calculate SROI is as following:

$$
\text { SROI }=\frac{(\text { Social impact value }- \text { Initial investment amount })}{\text { Initial investment amount }} \times 100
$$

Assigning a money value to the social impact can present problems, and various methodologies have been developed to help quantify the results. The Analytical Hierarchy Process (AHP), for example, is one method that converts and organizes qualitative information into quantitative values.

While the approach varies depending on the program that is being evaluated, there are four main elements that are needed to measure SROI:

- Inputs, or resources investments in your activity (such as the costs of running, say, a jobreadiness program).

- Outputs, or the direct and tangible products from the activity (for example, the number of people trained by the program).

- Outcomes, or the changes to people resulting from the activity (i.e., new jobs, better income, improved quality of life for the individuals; increased taxes for, and reduced support from, the government).

- Impact, or the outcome less an estimate of what would have happened anyway.

\section{Research and Development and ROI}

Despite other businesses, research and development is a process which results in a particular product or service. Output of a research initiative may be translated into an innovative process or improvement in a social service. Sometimes a research project terminate without a tangible achievement but leaves outstanding experiences for new projects. These kind of gains always is ignored in ROI calculations. In addition to experiences, some other gains also is achieved through research and development which are important but do not counted in ROI formula. A new formula will be as following.

$\mathrm{R} \& \mathrm{DROI}=\frac{(\text { Gain from Investment }+ \text { Social Impact Value }+ \text { National Prestige }+ \text { Perpetuated gains })-\text { Cost of Investment }}{\text { Cost of Investment }} \times 100$

The R\&D returns not only include direct returns on investments but covers social impacts of the investment and organizational and national prestige which influencing the gains from the investment. Companies with higher expenditure on research and innovation, get more attentions and supports from customers because of the potential impact of R\&D on quality measures. In other hand, governments indicating their likelihood to sustainable development and science advancement by increasing R\&D budgets and briefing it as a measure to increase their popularity among voters and taxpayers.

\section{Research Design}

Besides depicting descriptive representation of background data for TMU, this research mainly was carried out using scientometrics techniques to analyze scientific performance of the university in terms of papers published in international peer review journal, citation to documents, citation and self-citation per paper, national and international collaboration rate and so forth. In addition we have done co-authorship analysis to depict individual and collective performance of faculty members. The data was extracted from Thomson Reuter's Web of Science (WoS) database. In the second phase, we have analyzed the expenditures of the university on R\&D to calculate the cost of each scientific achievement in terms of outputs and outcomes. Applications like Bibexcel, Notepad+, SPSS and other bibliometrics analysis kits have been performed. Finally, we approached to propose an ROI model of R\&D expenditures in the university. 


\section{Findings}

Tarbiat Modares University as a higher education institute which provides only postgraduate studies, is the second ranked university among Iranian universities. Research policies in the university tended to focus on quality research and publishing in world class impacting journals. Findings indicated that, researchers affiliated with TMU, have been published 12394 documents in the sources indexed in WoS from the beginning of the university up to 2015. In general, among the 11 types of documents, journal papers includes almost 84 percent of publications. Besides the publications in national journals which almost all are in Persian and are counted in a separate citation database ${ }^{1}$, more than 99 percent of documents have been published in English.

The first document published was in 1994 near to 4 years after the establishment of the university. The main increase in publishing starts from year 2000 and 2015 witnesses the most publications by TMU researchers. Publications by researchers affiliated with the university have been increased from 107 in 2000 to 2500 in 2016 . This indicates more than 20 fold growth in terms of tangible research out puts.

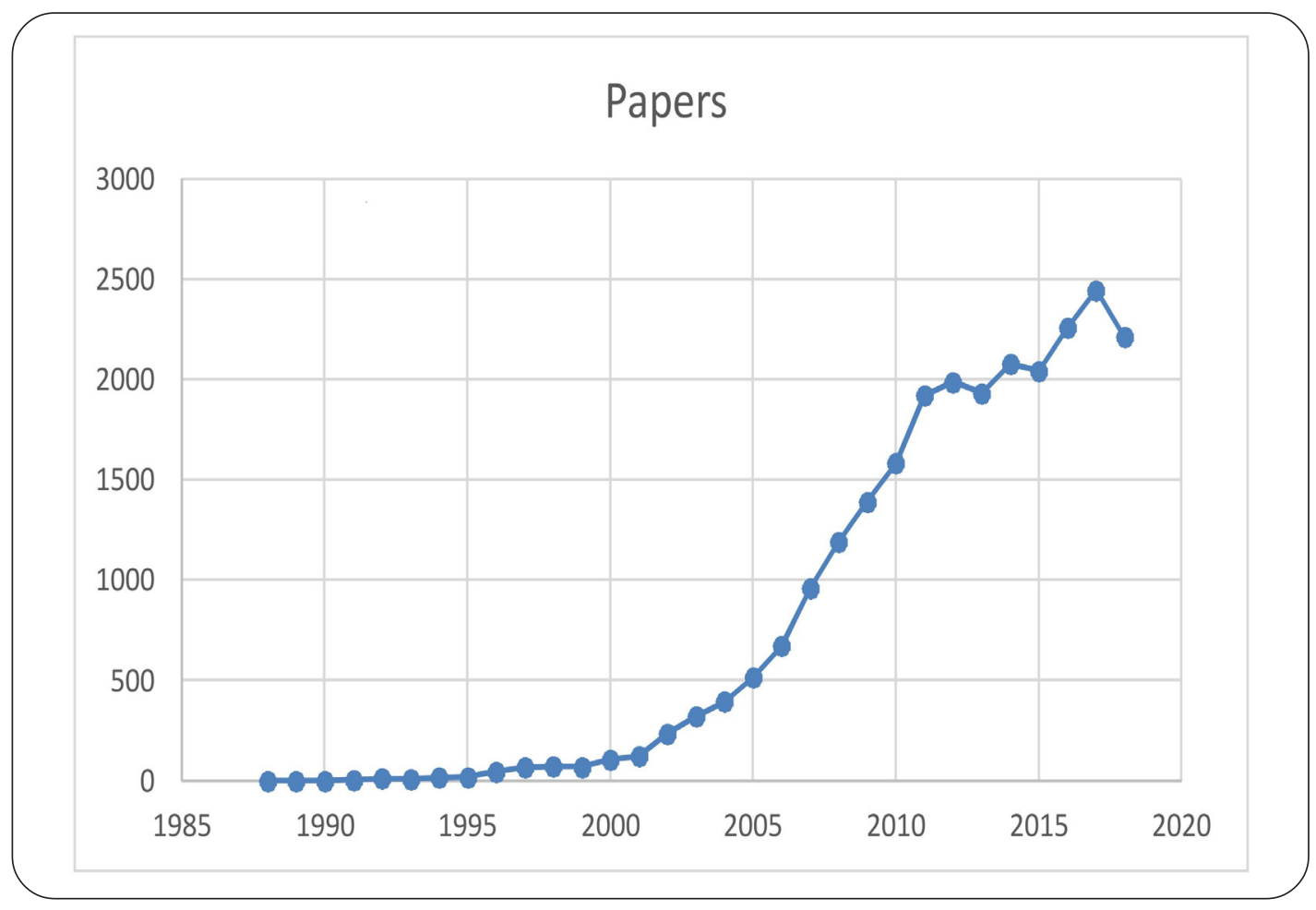

Figure 1. Increase in scientific production by Tarbiat Modares University (Clarivate Analytics, 2015)

Expenditure in research affairs as an index of input measures shows an increase in terms of 1000 dollar per paper. This means that, from year 2000 to 2016 expenditure per paper has been increased and this may interpreted as decrease in researchers' productivity and based on such a conclusion, university research policy makers, may be advised to decrease expenditure on research infrastructures.

But based on new R\&DROI formula we should consider the social impact and organizational and national prestige of the publications. Each publication in a prestigious journal, creates an opportunity to promote the university. Beyond that, findings of research which is reflected in scientific social networks may be used to solve several problems worldwide. Social impact and

${ }^{1}$ Iran recently has been established a citation analysis system under title ISC which stands for Islamic countries Science Citation in southern city Shiraz. This organization in collaboration with journal publishers in islamiccountries and in accordance with Organization of Islamic Coperation (OIC) bodies strives to analyze the R\&D outputs and performance.

\begin{tabular}{lllllll}
\hline $118 \quad$ Journal of Information \& Systems Management & Volume & 8 & Number & 4 & December 2018 \\
\hline
\end{tabular}




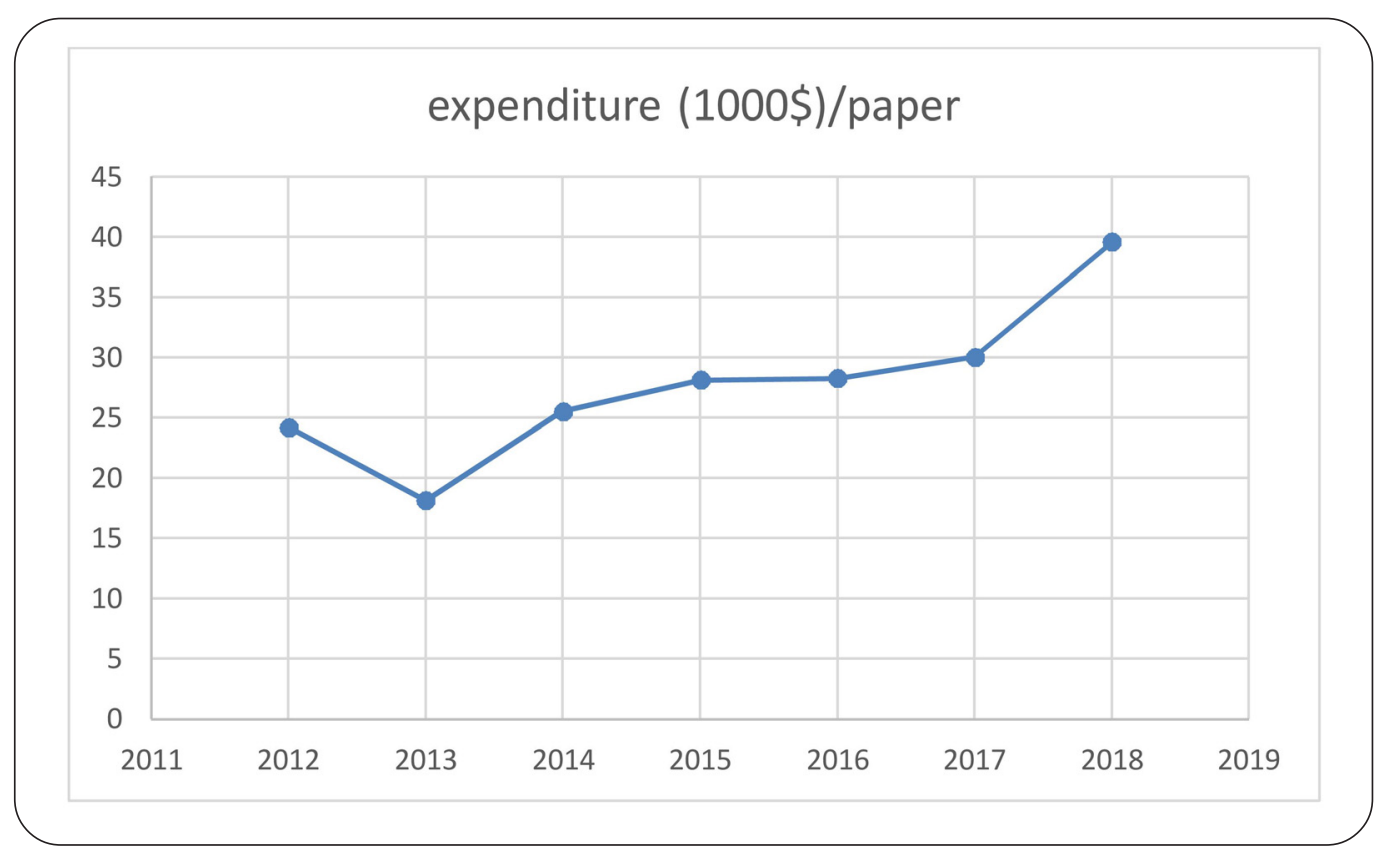

Figure 2. Mean expenditure per paper in Tarbiat Modares University (Saber and Hassanzadeh, 2016)

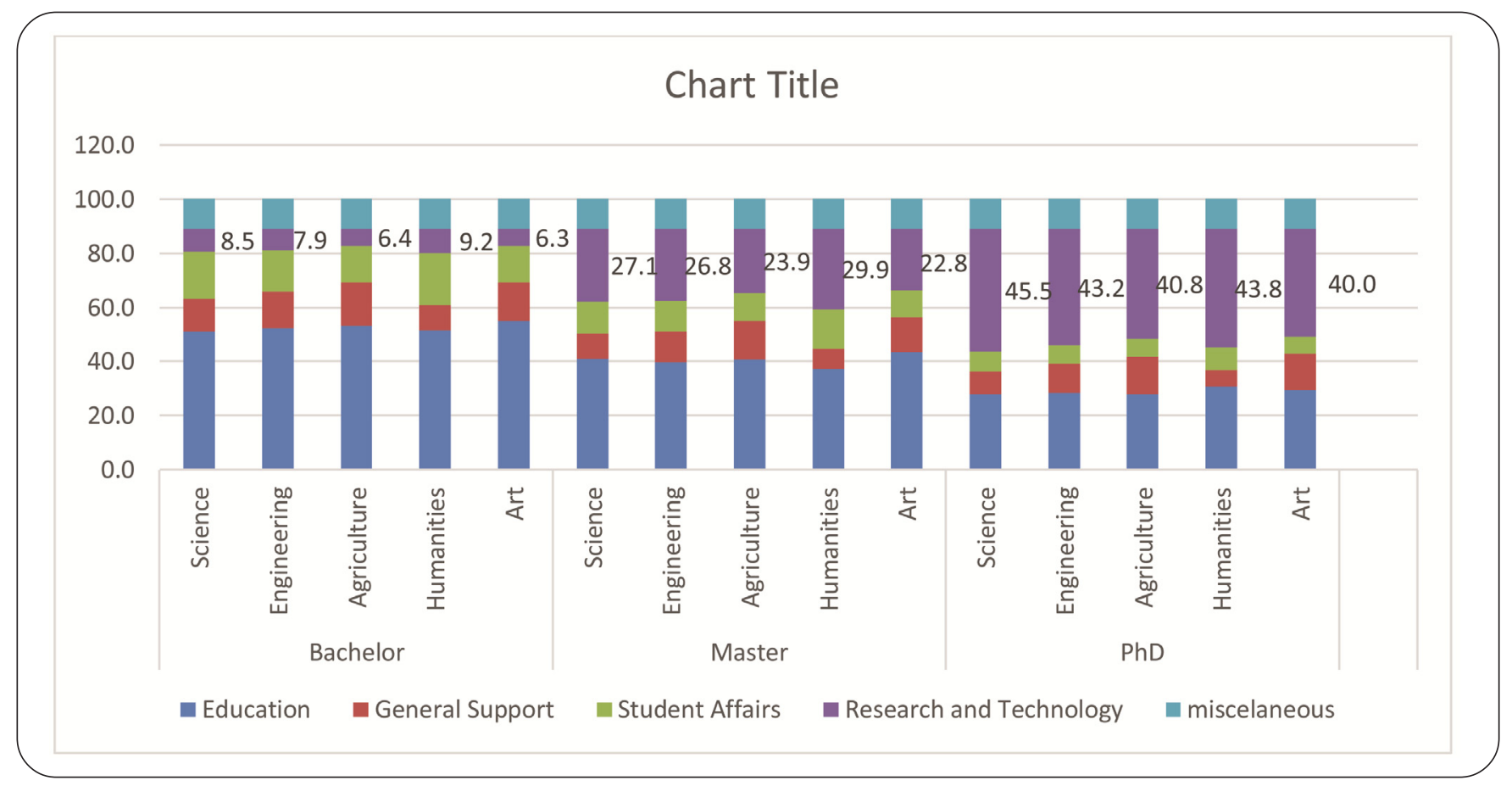

Figure 3. Share of research and technology expenditures by items, different science areas and degree

prestige as an element of return in research expenditures persuade policy makers in organizational and national levels to endure their support of research affairs.

Expenditure on research tremendously varies from bachelor to $\mathrm{PhD}$ degrees. While in bachelor degrees only 6 to 8.5 percent of expenditures goes to research affairs, this rate hikes to more than 45 percent in $\mathrm{PhD}$ degrees. The increase in investment on 
research in higher degrees has its roots in the tendency of these courses to focus on research and scientific out puts. Students entering in post-graduate studies mainly approaching towards a research initiatives. The more university authorities engaging in research impact, the more return on investment is realized. Emphasizing on research impact will increase the return rate as well.

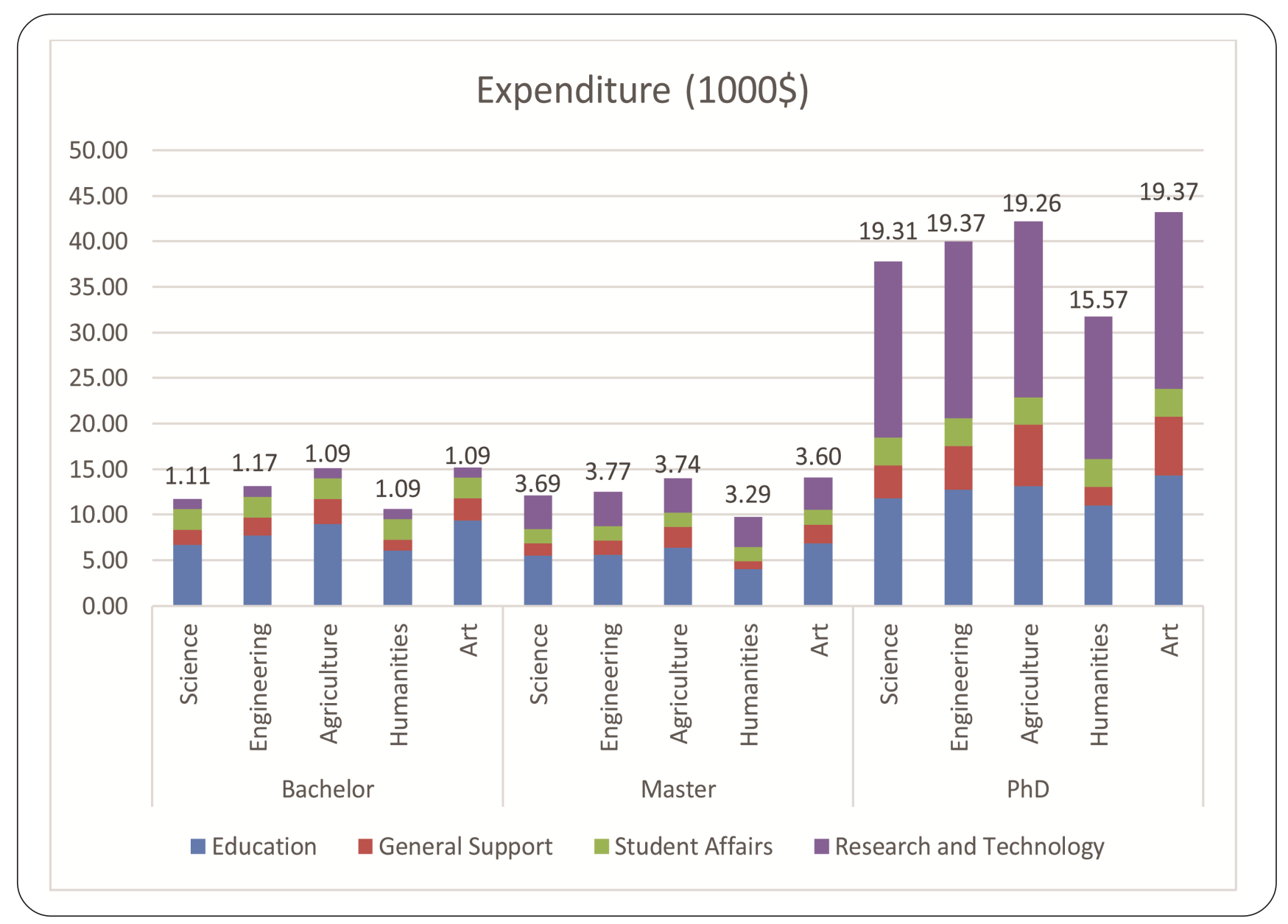

Figure 4. Expenditure on research in different science areas by degree $(1000 \$)$

Expenditure on education including research and development increases moving from bachelor to $\mathrm{PhD}$ degree. Share of research from total expenditures increase in higher degrees. Tremendous increase in expenditures on research and development initiatives in universities only can be justified by entering the new components to the formula as explained in the previous section. By including organizational, national prestige and contribution to the global knowledge which in turn contributes to the global sustainability we will be able to calculate return of investments on research and development. Quantifying all factors which deserve to be included in the formula will result in a comprehensive ROI model.

\section{Concluding Remarks}

R\&D expenditures also shows the same journey as the publications. R\&D expenditure well predict the scientific outputs but the main problem is that, financial investment in universities comes from various sources with various objectives. While government and social service sector expenditure on $R \& D$ targets national prestige and public responsibility on science, industry investment more intended to develop a prototype or a process kit. Formulating these heterogeneous elements in a framework will be the outstanding contribution to the scientometrics discipline.

A new model of ROI for research and development will include following components:

\begin{tabular}{lllllll}
\hline 120 & Journal of Information \& Systems Management & Volume & 8 & Number & 4 & December \\
\hline
\end{tabular}




\section{Total Expenditure (1000\$)}

60.00

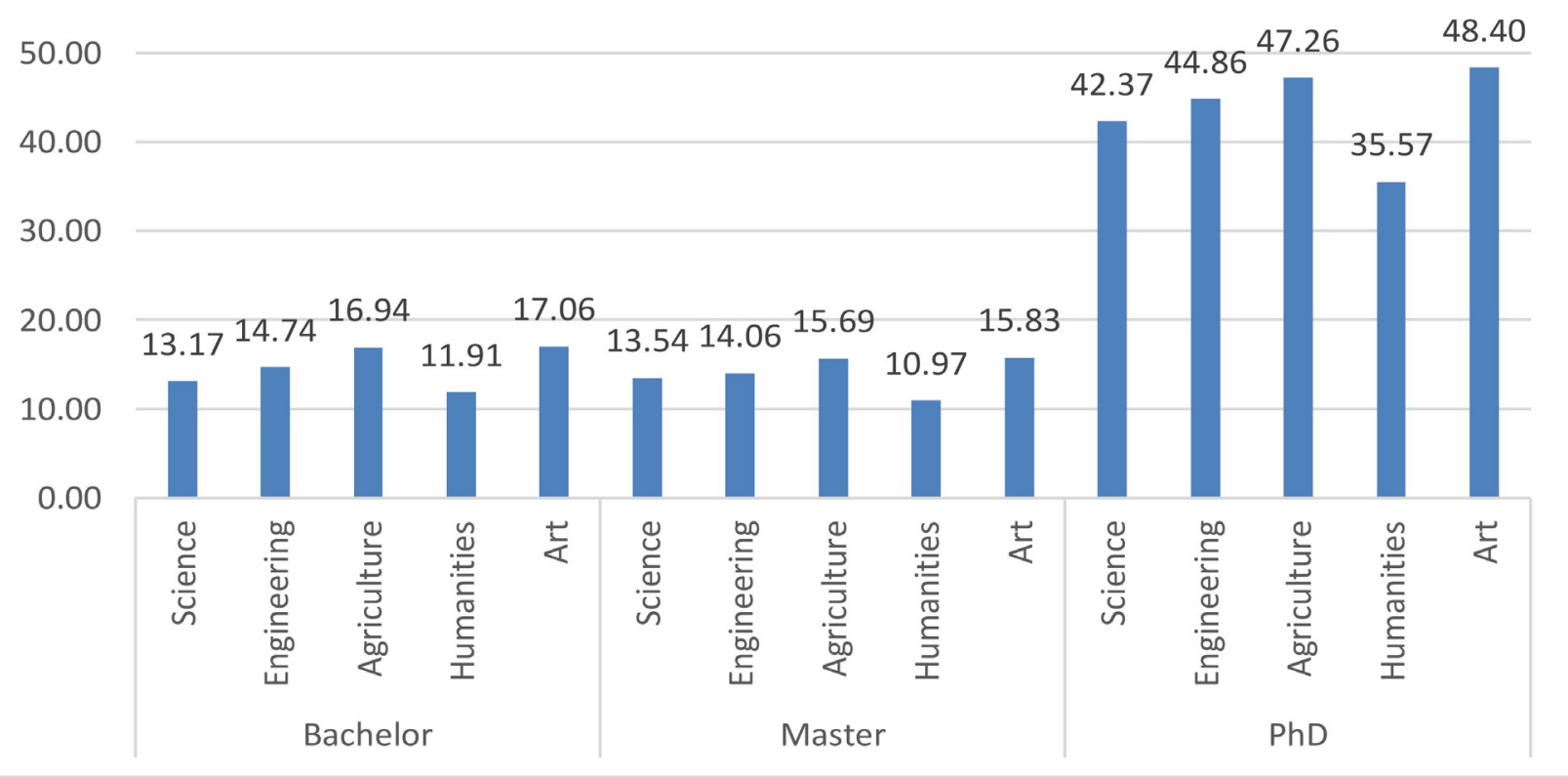

Figure 5. Total expenditures by degrees $(1000 \$)$

\section{- Investments}

1. Research personnel salary

2. Technical infrastructure including scientific resources, materials, laboratories and etc.

3. Miscellaneous costs

4. Investments

\section{- Gains}

1. Direct incomes

2. Social impact

3. Sustainability measures

4. Knowledge and learning

5. Savings in future projects

6. Skills and competencies

Since some of the mentioned components are qualitative they need to be qualified, consolidated and formulated towards a comprehensive model.

\section{References}

[1] Hassanzadeh, Mohammad., Akhgar, Babak., NAVIDI, Fatemeh. (2014). Integrating Knowledge and Science indicators 
(Kientometrics) towards a rational framework of investigations: a comparative approach. Collnet Journal of Scientometrics and Information Management, 8 (2) 247- 256

[2] Investopedia. (2018). Online Resource. Entry: ROI. Retrieved: 2018/07/21.

[3] Investopedia. (2018). Online Resource. Entry: SROI. Retrieved: 2018/07/21.

[4] Saber, M. (2016). Investigation on the research productivity of Tarbiat Modares University. Thesis - M.A. . Tarbiat Modares University. Supervisor: Mohammad Hassanzadeh. Tehran, Iran. 